\title{
Comparative Assessment of Natural and Artificially Ripened Tomatoes and Effects on Storage Life
}

\author{
Nargis Akter, A. K. Obidul Huq, Shamoli Akter, Md. Jahangir Alam*, Md. Majharul Islam, \\ Md. Jabbar Hossain, Nadira Tanzum Urmi
}

Department of Food Technology and Nutritional Science, Mawlana Bhashani Science and Technology University, Tangail, Bangladesh

Email address:

jahangirftns@gmail.com (Md. J. Alam)

${ }^{*}$ Corresponding author

\section{To cite this article:}

Nargis Akter, A. K. Obidul Huq, Shamoli Akter, Md. Jahangir Alam, Md. Majharul Islam, Md. Jabbar Hossain, Nadira Tanzum Urmi. Comparative Assessment of Natural and Artificially Ripened Tomatoes and Effects on Storage Life. International Journal of Nutrition and Food Sciences. Vol. 8, No. 4, 2019, pp. 59-62. doi: 10.11648/j.ijnfs.20190804.11

Received: August 26, 2019; Accepted: August 27, 2019; Published: September 17, 2019

\begin{abstract}
Tomato is most important vegetable crop of the world and is a rich source of vitamin A and C and other important nutrient and also referred as poor man's orange. Presently tomato is ripening by using artificial agent. In this regard an analytical study was conducted to study the chemical and microbial safety and shelf life of natural and artificially ripened (Calcium carbide and ethephon were applied) tomatoes in Bangladesh. In proximate analysis Moisture, Ash, Vitamin-C, Fat, Lycopene, PH and TSS of natural ripened tomato found $95.45 \%, 0.65 \%, 6 \mathrm{mg}, 0.098 \%, 20.61 \mathrm{mg}, 4.24,3.0 \%$ whereas in artificially ripened tomatoes it was found $92.64 \%, 0.59 \%, 4 \mathrm{mg}, 0.064 \%, 22.26,4.11,2.99 \%$ and $93.81 \%, 0.58 \%, 5 \mathrm{mg}, 0.072 \%$, $15.76 \mathrm{mg}, 4.24,3.1 \%$ respectively. In microbiological analysis, the Total Viable Count (TVC), Total Fungal Count (TFC) and Total Caliform Count (TCC) of natural and artificially ripened tomatoes were found safe level up to third days. But in $5^{\text {th }}$ days TVC in natural and artificially ripened tomatoes found $15 \times 10^{3} \mathrm{cfu} / \mathrm{g}$ and $12 \times 10^{3} \mathrm{cfu} / \mathrm{g}$ respectively which are higher than permitted value (BSTI Standard $10^{4} \mathrm{cfu} / \mathrm{g}$ ). TFC and TCC were also found highest in natural ripened tomato than artificially ripened tomatoes. From the microbial point of view natural and artificially ripened tomatoes were safe to consume up to 3 days but not in fifth days. In Bangladesh, the farmers are not much concerned about the microbiological safety and harmful effect of artificial agent so government administration and mass awareness are required to minimize its uses and ultimate effects.
\end{abstract}

Keywords: Tomato, Ripening Agent, Proximate Analysis, Microbial Safety, Shelf Life

\section{Introduction}

Tomato is mostly consumed vegetable of the world including tropical, sub-tropical and temperate regions thus a key product on the global agricultural market. Worldwide tomato ranks third in area and production after potato and sweet potato. Worldwide production of tomato accounts for $14 \%$ of total horticultural production. Bangladesh produced 0.60 million tons of tomato in 0.15 million hectares of land and the average yield being $9.4 \mathrm{t}$ ha-1 [1]. People of all age like tomato as vegetable as well as salad. The tomato consists of pulp and juice $97-98 \%$, skin $1.5-2.0 \%$ and seeds $1.0-1.5 \%$. The tomato is composed mainly of water soluble and insoluble solids, organic acids (principally citric acid) and micronutrients such as carotenoids and vitamins $\mathrm{A}, \mathrm{K}, \mathrm{C}$ potassium and is called as 'poor man's orange'. Among fruits and vegetables, tomato ranks $16^{\text {th }}$ and $13^{\text {th }}$ as a source of vitamin $\mathrm{A}$ and vitamin $\mathrm{C}$ respectively. Lycopene that imparts red color to ripe tomatoes is very important nutrient as it possesses anti-cancerous properties [2-3] reduce ovarian tumor growth [4] and prevent oral disease [5]. Tomato and its product can help to prevent CVD diseases [6-7] and provide an effective means against numerous type of cancers [8]. Generally, tomato undergoes six stages of ripening like green mature, breaker, turning, pink, light red and full red [9]. Usually tomatoes are harvested at the fourth stage (pink stage) of ripening [10]. Proper ripening is the final stage of development of a fruit which involves series of physiological and biochemical actions leading to various changes in color, flavor, aroma and texture that make the fruits both attractive and tasty. Tomato ripening is characterized by loss of 
chlorophyll and accumulation of carotenoids, mostly lycopene, as chloroplasts are converted to chromoplasts [11]. This total process of ripening occurred naturally in tomato but in recent times sellers artificially ripen green tomato even during the due season to meet the high demand and to make high profit. Ripening agent like calcium carbide is often utilized in Bangladesh to speed up the ripening process during winter months. However, calcium carbide is known to contain traces of arsenic and phosphorous so treatment of tomatoes with calcium carbide is may be extremely hazardous. Treatment of tomatoes by calcium carbide produce acetylene may affect the neurological system by inducing prolonged hypoxia gradually culminating to dizziness, headache, sleepiness, mood disturbances, mental confusion, memory loss [12]. Using of chemical such as ripening agents in tomatoes is one of the most burning issues in our country. Considering the above requirements, this study was designed to compare the chemical parameters and microbial safety of natural and artificially ripened tomato.

\section{Materials and Methods}

\subsection{Study Design}

An analytical study based on chemical and microbiological quality assessment of natural and artificially ripened Tomato and also evaluated its effect on storage life.

\subsection{Sample Collection}

Fully mature tomatoes were collected from airport horticulture area, Tangail. Ripening agents like ethephon were procured from local chemical shop and calcium carbide from the laboratory of Food Technology and Nutritional Science Department, Mawlana Bhashani Science and Technology University, Santosh, Tangail, Bangladesh.

\subsection{Place of Experiment}

The chemical and microbiological analyses were conducted in the laboratory of Food Technology and Nutritional Science Department, Mawlana Bhashani Science and Technology University, Santosh, Tangail, Bangladesh.

\subsection{Reagent Preparation and Apply}

After collecting mature tomato, they were then divided into three groups. Each group contains 10 mature tomatoes. One group (control group) was then kept for naturally ripened. Second group (Calcium carbide treated group) tomatoes were then treated with calcium carbide to artificially ripe and third group (Ethephon treated group) with ethephon to ripe. After ripening, all sample tomatoes were then kept for microbial analysis. Microbial analysis TVC, TFC and TCC were conducted at $1^{\text {st }}, 3^{\text {rd }}$ and $5^{\text {th }}$ day of ripen.

\subsection{Control Group}

To ripen naturally, control samples were put into separate carton box with straw and stored in separate room. Tomatoes were observed regularly and carefully. All the sample were monitored to note down the changes of peel color, stalk color, flavor, start point of spoilage and other physical properties. Each treatment was carried out double in number.

\subsubsection{Calcium Carbide Treated Group}

Calcium carbide was wrapped in a paper and dropped into separate cartons box containing tomatoes. All the bags were tied up and stored in the separate room.

\subsubsection{Ethephon Treated Group}

Ethephon were mixed with water in separated bowl and then tomatoes were submerged in it. After that tomato were pulling out from water and kept for the removal of water. Then the treated tomato putted into separate cartoon bags to ripe.

\subsection{Chemical Analysis of Tomato}

The proximate analysis was carried out in triplicate for moisture, ash, and fat contents by using oven drying, dry ash and Soxhlet apparatus methods respectively [13]. Vitamin-C (Ascorbic acid) content of tomato pulp was determined by the Bessey's titrimetric method [14]. Absorption determination for lycopene content was made by using Spectrophotometer UV-VIS SPECORD 205. Lycopene in the tomato samples was extracted with hexane: ethanol: acetone $(2: 1: 1)(\mathrm{v} / \mathrm{v})$ mixture following the method of Sharma and Le Maguer [15].

\subsection{Determination of Total Soluble Solid (TSS)}

Total Soluble Solid (TSS) contents of tomato were determined by oven drying method. A previously weighed empty, dry and clean flat bottom aluminum cup was taken. Nine $\mathrm{ml}$ of sample was weighed out into the cup. The cup was then placed on a hot place at $180^{\circ} \mathrm{C}$, until the residue begins to turned light brown. To ensure uniform evaporation the cup was pressed with the aid of a clean metal device, not touching the sample. For drying the cup was then placed into an oven operated at $100^{\circ} \mathrm{C}$ for $10-15$ minutes. After drying, the cup with dried sample was taken out from the oven and cooled in desiccators, for 5 minutes. After cooling, the cup with the dried sample was weighed out with the aid of a balance carefully. The loss in weight was the moisture content of the sample and the rest was dry matter or total solids. Percentages total solid of the sample was then calculated using the following formula:

$$
\text { Percent of total solids }=\frac{\text { Weight of sample after drying }}{\text { Weight of sample before drying }} \times 100
$$

\subsection{Estimation of $\mathrm{PH}$}

Sension TM+PH31, PH meter were used for determination of $\mathrm{PH}$. Checking the $\mathrm{PH}$ meter and make sure the $\mathrm{pH}$ meter has worked well. PH meter set in a dry place. Calibrate the meter containing a buffer solution of PH 4, PH 7 and PH 10. Whenever readings are taken correctly, ensure that the meter is worked correctly. After rinsing in distilled water, place the sample solution to be tested, then take the reading correctly. 


\subsection{Microbial Analysis}

Total Viable Count (TVC), Total Coliform Count (TCC) and Total Fungal Count (TFC) for tomato samples were done according to the method of The International Commission on Microbiological Specifications for Foods [16].

\subsection{Statistical Analysis}

Data collected from different parameters were subjected to statistical analysis by Statistical Package for the Social Sciences (SPSS, 20).

\subsection{Chemical Analysis}

Table 1. Chemical Analysis of natural and artificially ripened tomato.

\begin{tabular}{llll}
\hline \multirow{2}{*}{ Parameter } & Natural ripened tomato & Artificial ripened tomato & Ethephon \\
\cline { 3 - 4 } & & Calcium carbide & $93.81 \%$ \\
\hline Moisture & $95.45 \%$ & $92.64 \%$ & $0.58 \%$ \\
Ash & $0.65 \%$ & $0.59 \%$ & 5 \\
Vitamin C (mg/100g) & 6 & 4 & $0.072 \%$ \\
Fat & $0.098 \%$ & $0.064 \%$ & 15.76 \\
Lycopene (mg/100g) & 20.61 & 22.26 & 4.24 \\
P $^{\mathrm{H}}$ & 4.24 & 4.11 & $3.1 \%$ \\
TSS & $3.0 \%$ & $2.99 \%$ & \\
\hline
\end{tabular}

Table 1 represents the compositional analysis of natural and artificially ripened tomato. Moisture content found highest in natural ripened tomato $(95.45 \%)$ and lowest in Calcium carbide treated tomato (92.64\%). A slight variation was also found in ash content of natural and artificially ripened tomato. Highest ash content was found in natural ripened tomato which was $0.65 \%$ and lowest found in ethephon treated tomato which was $0.58 \%$. A noticeable change was found in vitamin-c content between natural and artificial ripen tomato. The vitamin-c content of natural ripen tomato was observed $6 \mathrm{mg}$ per $100 \mathrm{gm}$ whereas in Calcium carbide and ethephon treated tomato it was $4 \mathrm{mg}$ and $5 \mathrm{mg}$ per $100 \mathrm{gm}$ respectively. There was noticeable variation found in fat content of natural and artificial ripen tomato. Surprisingly

\section{Results and Discussion}

Different types of artificial ripening agents like calcium carbide, Ethephone are usually using to ripe the tomatoes commercially. Calcium carbide may contain traces of arsenic and phosphorus, both highly toxic to humans, and the use of this chemical for ripening is illegal in most countries. Ethephon may cause various side effects on human health. The main focus of the study was to identify any change of nutritional value and shelf life of natural and artificial ripened tomato.

\subsection{Microbial Analysis}

lycopene content in Calcium carbide treated tomato found highest compared to natural and ethephon treated tomato. The lycopene content of natural ripen tomato found 20.61 $\mathrm{mg} / 100 \mathrm{gm}$ whereas Calcium carbide and ethephon treated tomato it was found 22.26 and $15.76 \mathrm{mg}$ per $100 \mathrm{~g}$ respectively. The $\mathrm{P}^{\mathrm{H}}$ value of natural ripened tomato slightly different from artificially ripened tomato. The $\mathrm{P}^{\mathrm{H}}$ value found highest in natural ripened tomato (4.24) and lowest in calcium carbide treated tomato (4.11). Table 1 also shows that total soluble solids of natural ripen tomato and artificial ripen tomato. A slightly change was found in TSS content both natural and artificial ripen tomato. The TSS content of naturally ripen tomato was $3.0 \%$ and calcium carbide and ethephon treated tomato were $2.99 \%, 2.97 \%$ respectively.

Table 2. Total viable count of natural ripen and artificial ripen tomato.

\begin{tabular}{lllll}
\hline \multirow{2}{*}{ Days } & \multirow{2}{*}{ Natural ripened tomato } & \multicolumn{2}{l}{ Artificial ripened tomato } & \multirow{2}{*}{ Gulf Standard Maximum count permitted } \\
\cline { 3 - 5 } & & Calcium carbide & Ethephon & $10^{5}$ \\
\hline $1^{\text {st }}$ day of ripen & $4 \times 10^{3}$ & $2.5 \times 10^{3}$ & $2 \times 10^{3}$ & $10^{5}$ \\
$3^{\text {rd }}$ day of ripen & $8.5 \times 10^{3}$ & $7.5 \times 10^{3}$ & $7 \times 10^{3}$ & $10^{5}$ \\
$5^{\text {th }}$ day of ripen & $15 \times 10^{3}$ & $12 \times 10^{3}$ & $13 \times 10^{3}$ & \\
\hline
\end{tabular}

Table 2 indicates the TVC of natural and artificial ripen tomato at $1^{\text {st }}, 3^{\text {rd }}$ and $5^{\text {th }}$ day of ripen. According to Gulf Standard the TVC in ripened tomato is $10^{5}$. TVC in both natural and artificial ripen tomato was found below permitted value up to fifth day of ripen. Maximum TVC found in natural ripened tomato $\left(15 \times 10^{3}\right)$ at fifth day of ripen whereas lowest TVC found in ethephon treated tomato at first day of ripen.

Table 3. Total fungal count of natural ripen and artificial ripen tomato.

\begin{tabular}{lllll}
\hline \multirow{2}{*}{ Days } & \multirow{2}{*}{ Natural ripened tomato } & \multicolumn{2}{c}{ Artificial ripened tomato } & \multirow{2}{*}{ Gulf Standard Maximum count permitted } \\
\cline { 3 - 5 } & & Calcium carbide & Ethephon & $<10^{3}$ \\
\hline $1^{\text {st }}$ day of ripen & Nil & Nil & Nil & $<10^{3}$ \\
$3^{\text {rd }}$ day of ripen & $0.5 \times 10^{3}$ & $0.3 \times 10^{3}$ & $0.4 \times 10^{3}$ & $<10^{3}$ \\
$5^{\text {th }}$ day of ripen & $1.5 \times 10^{3}$ & $1.0 \times 10^{3}$ & $1.3 \times 10^{3}$ & \\
\hline
\end{tabular}


Table 3 indicates the TFC of natural and artificial ripen tomato at $1^{\text {st }}, 3^{\text {rd }}$ and $5^{\text {th }}$ day of ripen. The TFC count at first day of ripen were nil in all samples. Total fungal count in $3^{\text {rd }}$ day of natural, calcium carbide and ethephon treated tomato recorded $0.5 \times 10^{3}, \quad 0.3 \times 10^{3}$ and $0.4 \times 10^{3} \mathrm{cfu} / \mathrm{g}$ respectively which were below maximum permitted value of gulf standard. But at fifth day of ripen TFC of natural and ethephon treated tomato were found higher than maximum permitted value except calcium carbide treated tomato.

Table 4. Total Coliform Count of natural ripen and artificial ripen tomato.

\begin{tabular}{lllll}
\hline \multirow{2}{*}{ Days } & \multirow{2}{*}{ Natural ripened tomato } & \multicolumn{2}{c}{ Artificial ripened tomato } & \multirow{2}{*}{ Gulf Standard Maximum count permitted } \\
\cline { 3 - 4 } & & Calcium carbide & Ethephon & $<100$ \\
\hline $1^{\text {st }}$ day of ripen & Nil & Nil & Nil & Nil \\
$3^{\text {rd }}$ day of ripen & Nil & Nil & $0.06 \times 10^{3}$ & $<100$ \\
$5^{\text {th }}$ day of ripen & $0.08 \times 10^{3}$ & $0.05 \times 10^{3}$ & $<100$ \\
\hline
\end{tabular}

Table 4 indicates the TCC of natural and artificial ripen tomato at $1^{\text {st }}, 3^{\text {rd }}$ and $5^{\text {th }}$ day of ripen. There was no presence of Total Coliform Count found in natural and artificial ripen tomato at $1^{\text {st }}$ and $3^{\text {rd }}$ day of ripen. At $5^{\text {th }}$ day of ripen tomato Total Coliform Count was found $0.08 \times 10^{3}, 0.05 \times 10^{3}$ and $0.06 \times 10^{3} \mathrm{cfu} / \mathrm{g}$ in natural, Calcium carbide and ethephon treated tomato which were below the maximum permitted count of Gulf standard.

\section{Conclusion}

It may be concluded that, there was no significant difference found on chemical parameters in natural and artificial ripening tomatoes. Use of artificial ripening agent in tomato increased shelf life one day than natural ripening tomatoes. But these types of chemicals are most harmful and responsible for many life-threatening diseases like cancer, carcinogenesis, abnormal child in human beings. Considering its hazardous aspects, the use of artificial ripening agents must be strictly monitored and controlled. It is not solely the responsibility of the government; the people must also become aware and avoid consuming artificial ripening tomatoes.

\section{References}

[1] BBS. Yearbook of Agricultural Statistics of Bangladesh. Ministry of Planning, Government of the People's Republic of Bangladesh. 2011; 151 p.

[2] Hall RK, Singh P. Effect of Ethephon and Ethylene Gas on Ripening and Quality of Tomato (Solanum Lycopersicum L.) during Cold Storage. J Nutr Food Sci. 2013; 3: 244. doi: 10.4172/2155-9600.1000244.

[3] Palozza P, Simone RE, Catalano A, Mele MC. Tomato lycopene and lung cancer prevention: from experimental to human studies. Cancers (Basel). 2011; 3 (2): 2333-2357. Published 2011 May 11. doi: 10.3390/cancers3022333.

[4] Holzapfel NP, Shokoohmand A, Wagner F, et al. Lycopene reduces ovarian tumor growth and intraperitoneal metastatic load. Am J Cancer Res. 2017; 7 (6): 1322-1336. Published 2017 Jun 1.

[5] Gupta S, Jawanda MK, Arora V, Mehta N, Yadav V. Role of Lycopene in Preventing Oral Diseases as a Nonsurgical Aid of Treatment. Int J Prev Med. 2015; 6: 70. doi: 10.4103/20087802.162311

[6] M. Cámara V, Fernández-Ruiz, RM Cámara L. Domínguez MC, Sánchez-Mata. Tomato products and cardiovascular disease prevention. Acta Horticulturae. 2019; 1233, pages 201-208.

[7] Joye K. Willcox, George L. Catignani \& Sheryl Lazarus. Tomatoes and Cardiovascular Health, Critical Reviews in Food Science and Nutrition. 2003; 43: 1, 1-18, DOI: $10.1080 / 10408690390826437$.

[8] Barber N J and Barber J Lycopene and Prostate Cancer. Prostate Cancer and Prostatic Diseases, 2002; 5: 6-12.

[9] Suslow TV and Cantwell M. Tomato: Recommendations for Maintaining Postharvest Quality. Department of Plant Science, University of California, Davis. 2013.

[10] Wang X, Mao H, Han X and Yin J. Vision-based judgment of tomato maturity under growth conditions. African Journal of Biotechnology. 2011; 10 (18): 3616- 3623.

[11] Khudairi AK. The ripening of tomatoes. J Amer Sci. 1972; 60: 696-707.

[12] Huseyin P, Elim UL, Fatih AM, Akan MS, Efer U and Akan PL. Calcium carbide poisoning via food in childhood. $J$ Emerg Med, 2007; 32 (2), pp. 179-180.

[13] AOAC, Official methods of Analysis of AOAC, International, Washington, DC: Association of Official Analytical Chemist., $1985 ; 16,1985,15-46$

[14] Bessey OA, and King, CG. The distribution of vit-C in plant and animal tissues and its determination. J. Biol. Chem. 1933; 103: 68-73.

[15] Sharma and Le Maguer, Lycopene in tomatoes and tomato pulp fractions, Italian Journal of Food Science. 1996, 2, 107113.

[16] ICMSF. Microorganisms in Foods. Microbial Ecology of Food Commodities. 1998; 6: 615-616p. 